\title{
Weld Quality Assurance Practices in the Metal Welding Industries in Ghana
}

\author{
Akpakpavi Michael \\ Mechanical Engineering Department, Accra Polytechnic, Accra, Ghana
}

Email address:

micakpakpavi@yahoo.com

To cite this article:

Akpakpavi Michael. Weld Quality Assurance Practices in the Metal Welding Industries in Ghana. International Journal of Science, Technology and Society. Vol. 3, No. 4, 2015, pp. 111-119. doi: 10.11648/j.ijsts.20150304.13

\begin{abstract}
This study investigates the weld quality assurance practices in the metal welding industries in Ghana. The data for the study were collected using questionnaire, interview and personal discussions. One hundred and twenty informal sector welders, 80 formal sector welders, and 25 welding hardware shops/dealers were contained in the analyzed sample. The results of the analysis revealed that majority of the welding industries in the country lack weld quality assurance standards, weld quality testing equipments and materials as well as personnel to help assure weld quality practices in the metal welding industries. Also, equipments and materials for welding inspection and testing are not readily available in the welding hardware shops in the country. Moreover, even though most of the welders in the country have considerable years of working experience, they lack the skills of ensuring quality in their welding activities due to low levels of technical training. To instill professionalism into the welding industry, the suppliers should import the weld quality testing equipments into the country to be made available to the welders. The welders and the suppliers should take advantage of training programs offered by the training institutions in the country to enable them upgrade and update their knowledge and skills in weld quality assurance practices. The Government, the banks and other corporate organizations should help establish industries solely to produce more of the weld quality testing equipments locally in the country. This indeed, will help create more jobs and reduce the unemployment rates in the country.
\end{abstract}

Keywords: Ghana, Weld, Quality, Assurance, Practices, Industries

\section{Introduction}

\subsection{Background}

Welding activities in the Ghanaian welding and fabrication industry are classified under two sections: the formal and the informal sector. The formal welding sector comprises of companies operating under the metal production and manufacturing industries in Ghana and is classified as medium and large enterprises (MLEs). However, the informal welding sector consists of enterprises which are not recognized to be operating under the metal production and manufacturing industries in Ghana and are classified as micro and small scale enterprises (MSEs) [1].

The philosophy that often guides the fabrication of welded assemblies and structures is to "assure weld quality". Weld quality assurance is the use of technological methods and actions to test or assure the quality of welds, and secondarily to confirm the presence, location and coverage of welds. In manufacturing, welds are used to join two or more metal surfaces. Because these connections may encounter loads and fatigue during product lifetime, there is a chance they may fail if not created to proper specification [2]. It has been the goal of every metal welding industry globally to internalize, adopt and apply weld quality assurance practices in their welding activities. This will not only allow them to produce metal products that meet appearance and functional requirements, but also will enable them to remain competitive as welding firms in the worldwide market place [3].Welding as a manufacturing process has been practiced in almost all metal processing industries in Ghana in both the pre and post independence era. Unfortunately, however, quality assurance practices have not been injected and internalized by the metal welding industries particularly the micro and small welding firms that undertake most of the welding activities in the country. They lack the requisite knowledge in weld quality testing, and have not been able to achieve professionalism in their welding practices. A visit to most of the welding firms in both the formal and informal sectors across the country reveals that weld quality assurance practices are virtually absent in these enterprises. In fact, majority of them do not have basic weld quality tools and equipments as well as 
personnel to undertake weld quality tests to assure full compliance with standards.

The objective of this paper therefore, is to investigate weld quality assurance practices in the metal welding industries generally in the country. It is also to help educate and sensitize the welding industries in the country about the various weld quality testing methods and the need for the welding firms to start employing them in their welding practices.

\subsection{The Informal and Formal Welding Industries in Ghana}

The informal welding sector in Ghana comprises the micro and small scale enterprises (MSEs). The level of professionalism in this sector is low but welders in this sector are experienced as a result of constant practice in the welding trade. The main activities performed by this group include fabrication of plate and sheet metals, manufacturing of metal products, and maintenance and repairs of metallic products. Typically, some of their products include: cement block making machine, wagon and chassis (trucks), coal pot, fluid storage tanks, iron gates, car seat frames, billboards, burglary protection shield as well as agro processing products. The informal sector welding industry essentially employs basic hand tools in their manufacturing processes including hammer chisel, grinding tool, and drilling tool. The fabricator uses his energy colloquially termed as "man-power" in cutting these materials. Again, the welding processes used in this sector largely include shielded metal arc welding (SMAW) and sometimes oxyacetylene welding (OAW). Furthermore, in this sector, welding operations are mostly carried out in structures along the roadside and sometimes in miniature workshops and under trees. Indeed, most of the welding jobs are done on the floor and this process normally involves that welders have to squat during the welding process since welding benches are rarely used. Moreover, close to about $65 \%$ of welding jobs in this country are carry out by welders in this sector. Customers prefer to go to them for reasons of proximity, accessibility and relatively low works charges.

However, the formal sector of the welding industry in Ghana comprises of companies operating as medium and large enterprises (MLEs) registered in Ghana's trade register with clear-cut business objectives. The formal welding sector among other things designs and manufactures such products as palm kernel crackers, corn mill, block making machine, vegetable processing machine, metal tanks, containers, gas and oil tanks, pipeline construction and installation and reconstruction of mining equipment. Most of the firms in this sector employ such tools as machining centre, materials handling and storage centre, welding machines (SMAW), welding generator, lathe machine, bending machine, drilling machine, forklifts, cranes, oxyacetylene equipments as well as the basic hand tools in their metal processing activities.

\section{Methods}

\subsection{Study Area Description}

The study was carried out in five major industrial areas in
Ghana namely: Tamale, Kumasi, Takoradi, Accra and Tema metropolis. The study was confined to these areas because a large majority of the metal welding and fabrication industries as well as the renowned welding and fabrication hardware suppliers/dealers in the country are located in these areas. The researcher classified the metal welding industries into two categories. Category A consists of metal welding industries in the formal sector, registered in the Ghana's trade register as MLEs. Category B represents metal welding industries in the informal sector generally known as MSEs.

A visit was also made to recognized tertiary institutions in the country such as the Kwame Nkrumah University of Science and Technology, University of Mines and all the ten Polytechnics in the country to find out if they run higher diplomas and degree programs exclusively in metal welding and practice.

\subsection{Data Collection Techniques}

The study used multi approach techniques in data collection. It involved observation, personal discussions as well as questionnaire administration to workers from each category of metal welding firms and metal welding hardware suppliers/dealers identified in the country. This approach was used because of its complementary effect of strengths and weakness associated with each method. This approach was chosen to increase the validity of the study by enriching the scope, depth, and knowledge derived from the data.

\subsubsection{Observations and Discussions}

Observations and discussions were made by the researcher by visiting the two categories of the metal welding sectors as well as the welding hardware suppliers/dealers in the country. During the trip, information about welding quality assurance practices by the welding firms as well as weld quality testing equipment and tools available in the welding hardware shops in the country were observed and discussed. The observations made were essentially recorded on an observational chart.

\subsubsection{Survey}

The researcher administered pre-tested questionnaires to some metal welders outside the selected regions. Identified mistakes were corrected and question rephrased to avoid ambiguity. The questionnaires were administered to respondents from the two categories of welding sectors as well as welding hardware and equipments suppliers/dealers identified. The questionnaire comprised both the open and close ended questions. Questions were centered on metal weld quality assurance practices utilized by the firms, availability of adequate weld quality testing equipment and tools in the country, as well as capability of the welding firms to undertake weld quality testing procedures.

\subsubsection{Sampling}

In all, 225 metal welding workers and welding tools and equipments suppliers/dealers who responded to the questionnaire make up the sample size. 120 respondents were workers from the informal welding sector, 80 respondents were from the formal welding sector, while 25 constitutes the 
welding hardware suppliers/dealers in the country. The welders from the two welding sectors were randomly selected, whiles the welding shop owners, supervisors, foremen, and the owners of the welding hardware shops visited were purposively selected. The sampling size was strongly influenced by willingness of respondents to participate in the studies.

\subsubsection{Data Analysis}

Data extracted from the administered questionnaires and interview were analyzed using statistical tools such as pie charts and bar charts for percentile analysis [4].

\section{Results}

\subsection{Level of Technical Training of Welders}

With regard to level of technical training, about $15 \%$ of the informal sector welders who responded to the questionnaire had welding certificates (ordinary and intermediate certificates), whiles $85 \%$ responded having apprenticeship training. This finding is as pictured in fig. 1.

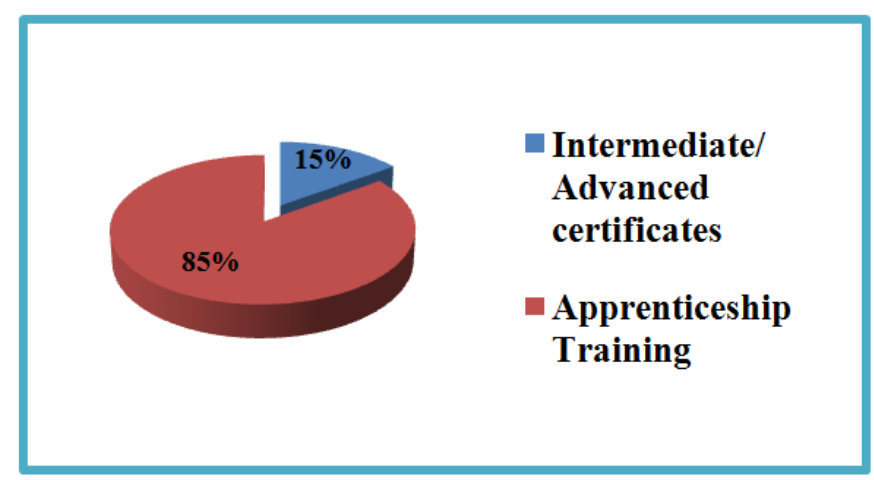

Fig. 1. Training levels of informal sector welders.

Moreover, the formal sector welders who responded to the questionnaire, about $11 \%$ had welding diplomas, $45 \%$ had intermediate welding certificates, $29 \%$ had advanced certificates whiles about $15 \%$ possessed training in the form of apprenticeship. This is illustrated in fig. 2 .

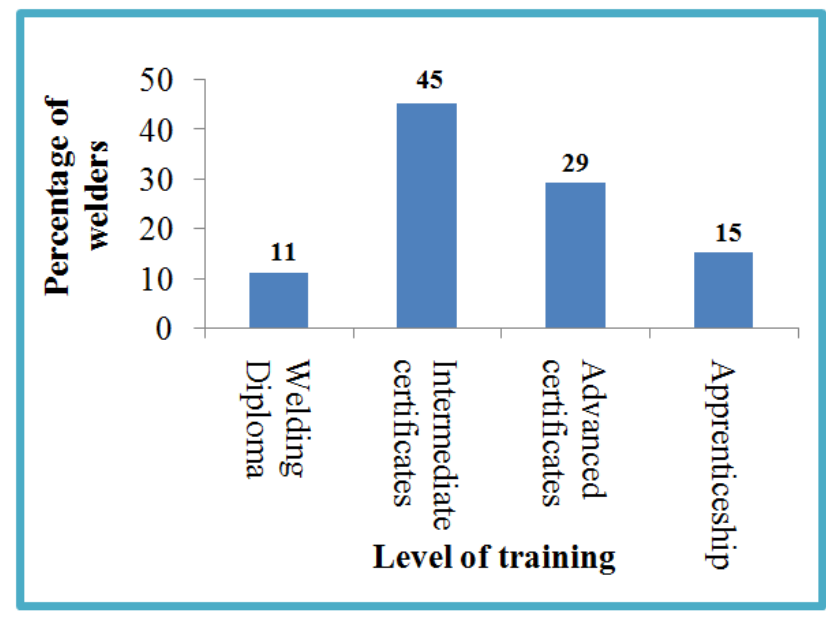

Fig. 2. Training levels of formal sector welders.

\subsection{Working Experience of Welders in the Formal and Informal Sector}

On the issue of number of years of working experience, $80 \%$ of the welders in both the formal and informal sector who responded to the questionnaire had more than 10 years working experience whiles the remainder $20 \%$ have had between 1-5 years working experience. This is depicted in fig. 3.

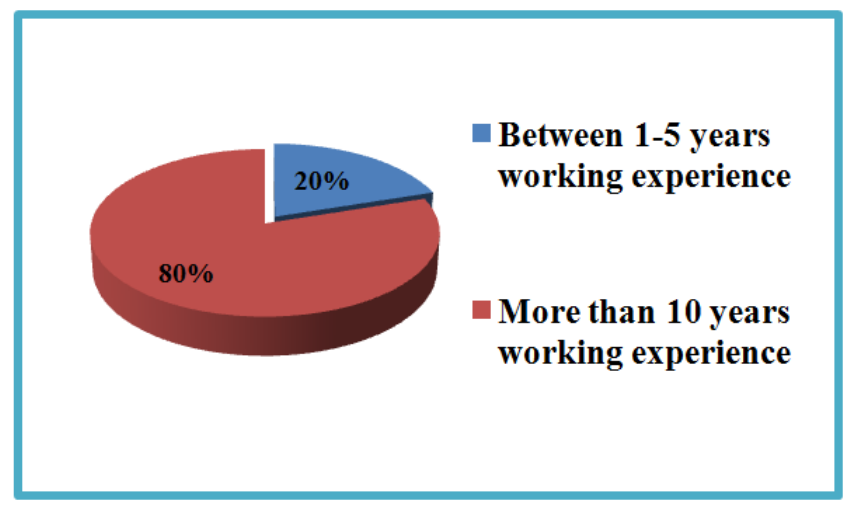

Fig. 3. Working experience of welders in formal and informal sector.

\subsection{Technical Training Areas of Welding Equipments and Materials Suppliers/Dealers}

The welding hardware shops who responded to the questionnaire on their technical training areas $12 \%$ obtained training in welding and other technical subject areas, $21 \%$ trained in marketing, $15 \%$ had trained in purchasing and supply, 24\% had accounting and booking keeping training whiles the remaining $28 \%$ had some form of entrepreneurial training/education. This finding is as pictured in fig. 4 .

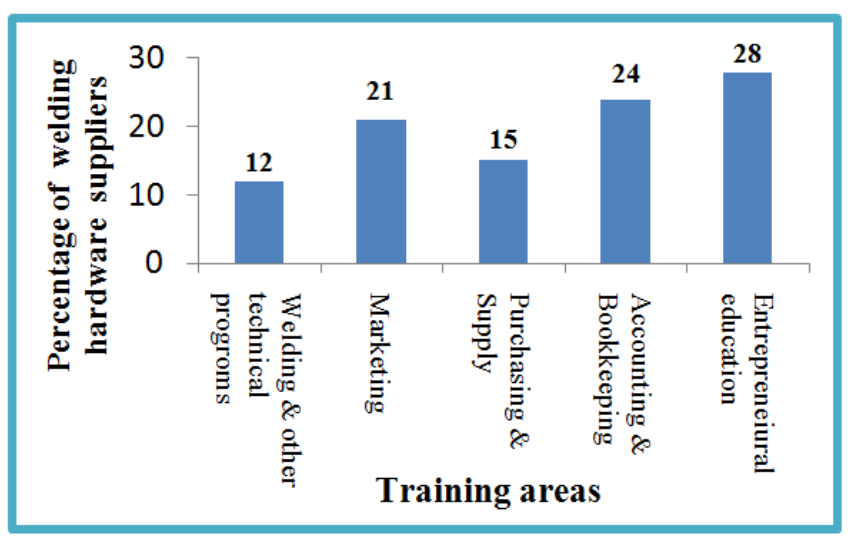

Fig. 4. Technical training areas of welding hardware suppliers/dealers.

\subsection{Availability of Weld Quality Testing Manuals/Standards in the Welding Industries}

On the issue of the availability of weld quality testing manuals/standards in the welding industries in the country, about $21 \%$ of the welders in both the formal and informal sector had weld quality testing manuals, whiles $79 \%$ did not have weld quality testing manuals/standards. This is shown in fig. 5 . 


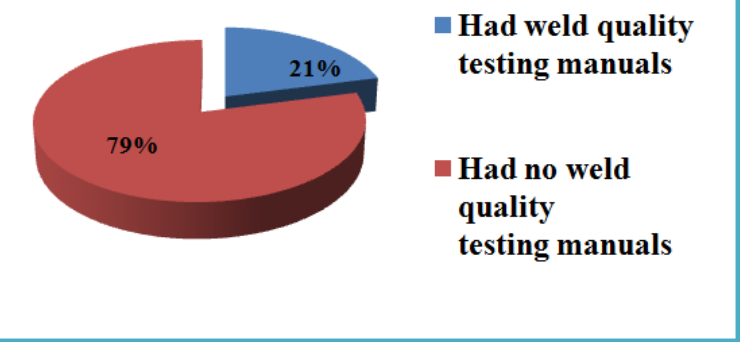

Fig. 5. Availability of weld quality testing standards in the welding industries.

\subsection{Availability of Weld Quality Testing Tools, Equipments \& Materials in the Welding Industries}

On the above issue, about $12 \%$ of the welders in the formal and informal sector in the country together had weld quality testing equipment, tools and materials in-house for weld quality testing activities, whiles $88 \%$ had no weld quality testing equipments. This is illustrated in fig. 6 .

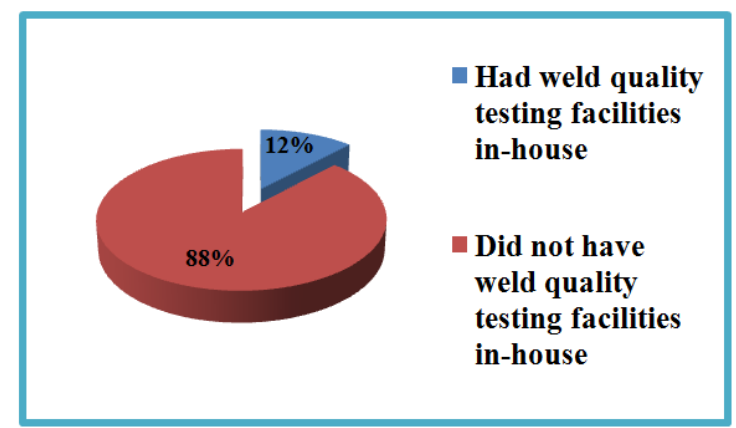

Fig. 6. Availability of weld quality testing equipments and materials in the welding industries.

\subsection{Availability of Welding Quality Assurance Personnel in the Welding Industries}

With regard to the availability of weld quality assurance personnel in the welding industries, only about $7 \%$ of the welders in the formal and informal welding sectors in the country who responded to the questionnaire indicated that they had certified weld quality assurance personnel in-house, whiles $93 \%$ did not have any certified weld quality assurance personnel. This finding is as illustrated in fig. 7.

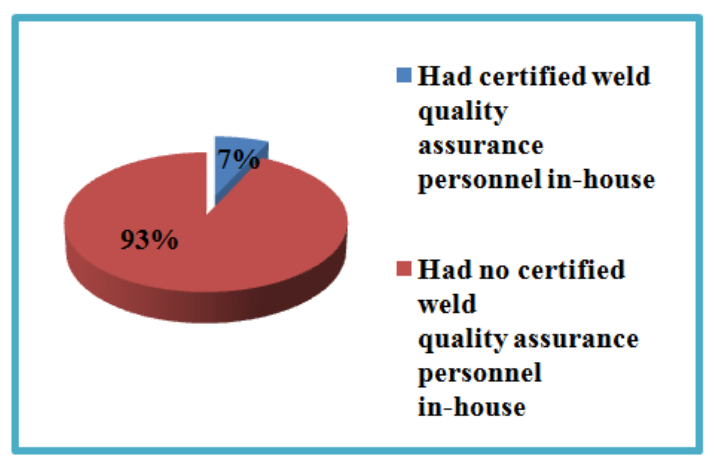

Fig. 7. Availability of certified weld quality assurance personnel in the welding industries.

\subsection{Availability of Weld Quality Testing Tools, Equipments \& Materials in the Welding Hardware Shops}

On the above issue, only about $5 \%$ of the welding suppliers/dealers who responded to the questionnaire said they had stocked and supplied weld quality testing tools, equipments and materials to the welders in the country. The remainder $95 \%$ had no stock of weld quality testing tools, equipments and materials. This finding is as depicted in fig.8.

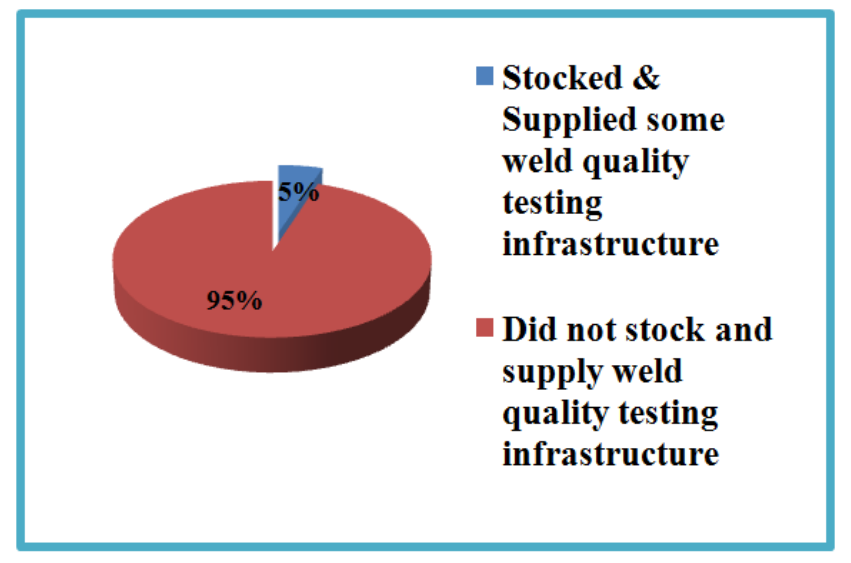

Fig. 8. Availability of weld quality infrastructure in the welding hard-ware shops.

\section{Discussion}

\subsection{Technical Training Levels of Welders}

Research available indicates that artisans with lower education and training are constrained by lack of adequate knowledge to enable them understand welding theory on their own. The research further shows that, higher level of education has a higher positive impact on weld products quality and this works to the effect that products made by artisans with primary education levels are of lower quality than those products made by their counterparts with secondary education levels [5].

Indeed, until recently, welding itself was a skill that craft people could learn without a real understanding of the science behind it. The scientific and engineering principles behind welding must replace the art of welding for it to achieve its potential as a preferred state-of-art manufacturing process [6]. To this end, there has been a paradigm shift in the training of welders in both the formal and informal training situations. Currently, welding training programs worldwide are designed to train welders not only to acquire the art of welding but also the scientific and engineering principles of welding. It is also expected of welders globally to possess high mathematics, reading, writing, oral and computer skills. In developed countries such as the USA, China, Germany and so on, students in formal or informal welding programs learn the art of heating and shaping metals. Required classes may include advanced mathematics, metallurgy, blueprint reading, welding symbols, pipe layout and a welding practicum [7]. Methods and techniques taught in welding classes include arc welding, soldering, brazing, casting and bronzing. Hands-on training 
often includes oxyacetylene welding and cutting, shielded metal arc welding, gas tungsten arc welding and gas metal arc welding. This is done to ensure that the products of their welding programs build successful careers in welding and remain competitive in the globalized market place. Certainly, welding education programs in these developed countries may culminate in a Welding Certificate of Achievement, Associate of Science in Welding or Bachelor of Science in Welding Engineering [8].

As identified in section 1.2, a chunk of metal welding activities in this country are carried out by welders in the informal sector due to reasons of proximity to customers and low works charges. Unfortunately, however, as indicated in figure 1, a very large number of these informal sector welders went through the apprenticeship form of training with few of them acquiring secondary and basic school educational levels. Majority of them are school dropouts. As a result of low educational levels, the welders in this sector can hardly read engineering drawings, drafts and other documents containing welding symbols. They are also completely unaware of the concepts of weld quality. Observations reveal that welders in the informal sector do not take time to properly design and prepare their welds and weld joints, select appropriate welding electrodes and other welding consumables, choose appropriate welding methods and above all, do not have the capacity to test and inspect their weld quality levels after welding operations. Indeed, even basic weld quality testing equipments and other welding logistical supports are virtually not available in the informal welding establishments.

In the formal sector, as indicated in fig. 2, most of the welders possess welding certificates (intermediate and advanced) qualifications essentially from the technical institutes in this country. From observations, the welders in the formal sector, by virtue of their training seem to understand weld quality concepts. Few of them try to achieve quality by taking the appropriate steps to ensuring weld quality before, during and after metal welding processes. They also have the capacity to read engineering drawings and drafts containing essentially welding symbols for proper weld design and execution.

Nonetheless, the level of weld quality check practices which is prerequisite for maintaining high quality standards in the welding industry in this country is rather low. Indeed, to help raise the quality levels of the metal welding carry out by the welders in both the formal and informal sectors, it is necessary that training institutions such as the universities, polytechnics, the technical training centers, Intermediate Technology Transfer Unit and so on organize in-service training for the welders in the country to help them upgrade and update their knowledge and competencies in weld quality assurance practices.

Moreover, a visit to the country's Science and Technology Universities as well as the ten Polytechnics which serves as training institutions in this country shows that none of these institutions runs a higher diploma or degree programs exclusively in welding and fabrication. They also do not have enough infrastructure and logistics on metal welding and essentially on metal weld quality inspection and testing as is the case in most universities and polytechnics in advanced countries. It is therefore, expedient that the government, the banks, as well the corporate organizations in the country help in providing adequate welding logistics in these institutions. As plans are advanced to convert the country's polytechnics into technical universities, the infrastructure, programs and curriculum of the polytechnics should be expanded and upgraded to enable some of them run degree programs exclusively in welding and fabrication. This will help train welding specialists and weld quality assurance experts locally in the country. It will also go a long way to guarantee professionalism in the country's welding sector.

\subsection{Working Experience of Welders in the Formal and Informal Sector}

Welding as a profession and as one of the main joining methods employ in industry has evolved to the extent that computer simulations are being employed globally to help detect stress levels and other defects before the commencement of the main welding process. Again, highly precise fabrication is being demanded, and so microstructure and distortion control are very important. It is significant to determine welding process conditions by considering combinations of the various aspects of "process mechanics," including the appearance of a bead, penetration shape through a cross-section, fabrication efficiency, microstructure, weld defects during and after welding, environment, thermal distortion, residual stress, and so on [9-10].

Majority of the welders in both the formal and informal sector have more than ten years working experience as identified in section 3.2. Nonetheless, despite their long number of years of experience in the welding sector, observations reveals that, the welders, particularly those in the informal sector and some few ones even in the formal sector lack knowledge in basic welding procedures and methods. Obviously, they seem to lack adequate knowledge in basic metal welding concepts such as: acceptable levels of metal residual stresses, weld distortions, heat-affected zone (HAZ) properties, and welding defects including cracks, distortion, gas inclusions (porosity), non-metallic inclusions, lack of fusion, incomplete penetration, lamellar tearing, and undercutting.

Surely, in order to ensure a display of professionalism in the welding industry, it is imperative that the welders in the country take advantage of in-service training programs offered by technical training institutions such as Danest Weld located in Takoradi, Gratis foundation, ITTU and so on to upgrade their professional competency levels particularly in weld quality inspection and tests procedures. The welding sector, essentially those in the formal sector should endeavor to introduce computer weld simulations in their welding activities in order to enable them infuse efficiency, effectiveness and competiveness in their welding activities and in the welding sector in the country at large. 


\subsection{Technical Training Areas of Welding Equipments and Materials Suppliers/Dealers}

Welding sales representatives serve a very important function in the welding industry. They are the conduit for information concerning new technologies that can improve the productivity, reliability, and more importantly, quality of welding processes. In the USA, Germany, China, India and elsewhere, knowledgeable welding sales representatives offer manufacturers /customers' invaluable technical support and guidance in the appropriate application of welding technologies. They also give technical advice on weld quality to their customers [11]. Currently, developments in ICT has even make it possible for customers in the welding sector worldwide to buy products, check specifications and compare prices over the internet and many frown on the idea of having to waste time on technically untrained people who are little more than a walking brochure. In most developed countries and elsewhere it is expected of welding supply industry representatives/dealers to be trained to the highest level and must be able to give accurate information with regard to the correct welding procedures to adopt, the most appropriate equipment for the application, give crucial information on the latest Health \& Safety requirements as well as maintain a high standard of professional and ethical conduct [12-13].

However, as identified in figure four of this paper, only a small number of the welding equipments/suppliers in the country have certificates in welding and other required technical areas. A very large number of the suppliers in the country rather trained in non technical areas. An informal discussion with the dealers shows that a majority of them knows virtually nothing about welding processes, welding methods as well as quality issues in welding. The dealers/suppliers also lack the ability to give expert advice to welders on appropriate welding equipments, materials, tools, welding consumables etc. This indeed, is largely due to the suppliers/dealers lack of training in the appropriate technical areas such as welding, metallurgy and mechanical engineering which is rather the case in other jurisdictions.

Moreover, the situation whereby a hefty number of the welding equipment suppliers/dealers in the country do not possess the requisite technical qualifications does not portend well for the welding industry in Ghana. It is actually expected of the suppliers not only to furnish their equipments to the welding industry, but also be in a position to offer connoisseur information on welding materials, equipments, welding methods, welding standards, weld quality information and so on. They are also expected to have knowledge about the welding supplies required by the welding sector and therefore make them available in the hardware shops. Hence, it is expected of the welding hardware suppliers in the country to take advantage of training programs offered by the technical training institutions in the country as well as abroad to enable them enhance their technical competencies. This will go a long way to sanitize the welding sector and inject professional and quality in the welding industry in the country.

\subsection{Availability of Weld Quality Assurance Standards/Policy in the Welding Industries}

To provide a well-defined basis for planning welding operations and to ensure a system for quality control during welding, it is important that organizations involve in welding issue the relevant welding procedure specifications, ensure that welders are qualified and appropriately trained and tested to do the work safely and precisely. Today, the metalworking industry worldwide has instituted weld quality assurance standards to guide welders, weld inspectors, engineers, managers, and property owners in proper welding technique, design of welds, how to judge the quality of weld, Welding Procedure Specification, how to judge the skill of the person performing the weld, and how to ensure the quality of a welding job [14-15-16]. However, as indicated in figure five of this report, a very large number of the welding industries in the country do not have welding quality policy nor are certified under any welding quality assurance standards. The few companies that have weld quality policy are essentially in the formal welding sector and they operate under standards such as the ISO 9001 and ISO 3834 welding quality standard.

Additionally, those welding industries in the formal and informal welder sectors which do not have any welding quality policy nor are certified under any welding quality assurance standard perform welding operations based on standards provided to them by their customers. Hence, in the absence of quality welding standards, the welding firms carry out welding operations under no quality standard. However, the few welding industries in the country who utilize quality standards in their welding activities do obtain the standards from third party certification bodies including: American Bureau of Shipping (ABS), Bureau Veritas (BV), British Standards (BS), American Society of Mechanical Engineers (ASME), as well as some domestic certification bodies such as Sonic Control Engineering, and Probe Engineering.

Undoubtedly, this situation whereby a very large majority of the welding firms in the country do not work to any standard specification is rather unfortunate. This indeed means that professionalism and adherence to acceptable quality levels are virtually absent in the welding industry in the country. To help address this situation, it is crucial that the Ghana Standard Boards, the Garage Association of Ghana, the Ministry of Trade and Industry, as well as the relevant regulatory bodies in the country ensure that the actors in the welding sector adopt and adapt the use of quality assurance standards in their welding activities. This will not only bring about sanity in the welding sector but will also raise the efficiency and competency levels of the welders in this country. The oil and gas industry in the country will also be more than willing to assign contracts to the welding firms in the country. 


\subsection{Availability of Weld Quality Testing Equipments and Materials in the Welding Industries}

Many distinct factors influence the strength of welds and the material around them, including the welding method, the amount and concentration of energy input, the weldability of the base material, filler material, and flux material, the design of the joint, and the interactions between all these factors. As a result of this, welds are normally tested to specifications to help detect, control and correct defects in weld joints prior to usage. To test the quality of a weld, either destructive or nondestructive testing methods are commonly used to verify that welds are free of defects, have acceptable levels of residual stresses and distortion, and have acceptable heat-affected zone (HAZ) properties. Typical welding defects include cracks, distortion, gas inclusions (porosity), non-metallic inclusions, lack of fusion, incomplete penetration, lamellar tearing, and undercutting. The common non-destructive methods are: Visual Inspection-this employs testing equipments such as rulers, fillets, fillet weld gauges, squares, magnifying glasses, and reference weld samples; Dye Penetrant Test-this employs fluorescent penetrating liquids and developers; Magnetic Particle Test-this employs iron particles or fluorescent, ultraviolet light; Radiographic Testthis employs X-ray or gamma ray, film processing and viewing equipment, penetrameters; Ultrasonic Test-this employs ultrasonic units, probes, and reference comparison patterns. A few examples of destructive testing include macro etch testing, fillet-weld break tests, transverse tension tests, guided bend tests, acid etch testing, back bend testing, tensile strength break testing, nick break testing, and free bend testing [17].

Moreover, most of the afore-mentioned welding testing equipments are available in the shop-floor and laboratories of the metal welding industries in most developed as well as developing countries such as India and Malaysia [17-18-19]. Unfortunately, however, as depicted in figure six of this report, large majority of the metal welders in the informal and formal sector in the country have no or inadequate weld quality testing equipments and materials at their shop-floor or laboratories. Discussion with the welders shows that they are not able to procure these equipments due to inadequacy of capital investments and financial difficulties. The situation is such that the few formal sector welders who particularly manufacture oil and gas equipments undertake weld quality assurance activities. This they essentially do by relying on outside weld quality testing firms both locally and abroad upon request by their customers. In the informal sector, apart from not having the technical knowledge and expertise to carry out weld quality testing activities, they also do not have enough capital to procure the needed weld quality testing equipments. The consequence of this is that a very large number of the welding industries in the country do not have weld quality testing equipment and materials in place for weld quality testing purposes, which is undesirable.

Nonetheless, to be able to compete favorably in the globalized market place, and to inject efficiency and effectiveness in their welding activities, it is crucial that the welding establishments in the country procure the relevant weld quality testing equipment and utilize the latter to enhance their weld quality levels. The informal welding sector which have been characterized by low capital investments should endeavor to acquire visual weld quality testing equipments such as: Rulers, Magnifying Glass, Squares, Dye Penetrants, Pocket Telescopic Inspection Mirror, Oval Inspection Mirror, Welding Profile Gauge, Digital Pit Depth Gauge, Fillet Weld Gauge /Calculator, Pre Inspection Pocket Fillet Weld Gauge, Taper Gauge, Dial/Pit Depth Gauge, reference weld samples. These are relatively easier to use and are also cost effective. Additionally, the formal sector welders with relatively large capital investments can obtain the afore-mentioned simple weld quality testing equipments in addition to the more advanced equipments such as: Magnetic Particle Test Sets, Radiographic Test Sets, Ultrasonic Test Equipments, WeldPrint analyzers, computer software simulation packages on weld quality test etc.

Certainly, as indicated in section 3.1 of this report, more than 60 percent of the welders in the country are in the informal sector and had their training through the apprenticeship system of training. Hence, by procuring these basic testing equipments the trainees/learners in the apprenticeship metal welding training system will become aware of the basic concepts in weld quality testing and will also be pre-disposed to the use of weld quality testing equipments. The trainees will then be willing to internalize and practice them in their welding activities after their training programs. This will go a long way to bring about sanity and professional in the welding sector generally in Ghana.

\subsection{Availability of Welding Quality Testing Personnel in the Welding Industries}

To do high-performance welding, it is important for a company to have a quality weld inspection program in place. Welding inspection requires knowledge of weld drawings, symbols, joint design, procedures, code and standard requirements, and inspection and testing techniques. In order to do so, a company must have a welding inspector who is formally qualified and capable of performing a number of different testing methods or have the necessary knowledge and experience to conduct weld quality inspection. It is not practical for a person who is not well-versed in the necessary procedures to perform this task [19]. Welding enterprises in most developed and developing countries around the world tend to employ qualified welding inspectors who have the responsibility to be personally present where the welding operation is conducted. These on-site welding inspectors ensures that good quality welds are achieved, specifically by monitoring items such as: welders' certificates, weld joint preparation, condition of electrodes, welding technique, welding current, welding machines and tools, slag cleaning, incomplete welds and other similar tasks [20-21].

Unfortunately, a very large majority of the welding enterprises in both the formal and informal sectors have not been able to mobilize welding team which essential includes 
certified weld quality assurance personnel as illustrated in fig.7. Certainly, weld quality demands that quality be built into a product right from the onset of the weld, but not after welding operations. The absence of certified weld quality assurance personnel in the welding industries in the country means that weld quality is checked in these firms only after welding operations but not before and during welding activities. In the informal welding sector, weld quality testing is hardly done, hence, a significant proportion of them do not employ the services of weld quality assurance experts on-site. However, in the formal welding sector some few of them do undertake weld quality testing by employing the services of external testing officers. Additionally, an informal interaction with most of the formal sector welding firms reveals that they hardly employ permanent weld quality assurance staff.

Obviously, the situation whereby majority of the welding firms do not permanently engage the services of weld quality assurance experts is rather not a healthy situation. Definitely, the engagement of permanent weld quality assurance staff may increase labor cost of welding; nevertheless, their presence in the welding industries will rather enable the latter to be noted for producing quality weld products and reduce their cost of fabrications. The welding firms will also stand a chance of gaining both local and international recognition and contracts.

\subsection{Availability of Weld Quality Testing Tools, Equipments \& Materials in the Welding Hardware Shops}

Fig. 8 shows that about $95 \%$ of the welding hardware shops in the country have not been able to stock weld quality testing tools, equipments and materials for sale to welders. A visit to the renowned welding hardware shops in the country and in the study locations reveals that most of them deal in assorted welding supplies including: welding machines, welding electrodes and other welding consumables, welding shields, helmets, gloves, hacksaw blades, grinding stones etc. However, interactions with the suppliers/dealers show that they hardly stock weld quality testing equipments for sale to the welders. The situation is such that even simple visual weld inspection and testing equipments such as Rulers, Magnifying Glass, Squares, Dye Penetrants, Pocket Telescopic Inspection Mirror, Oval Inspection Mirror, Welding Profile Gauge, Depth Gauge, fillet gauges, magnetic particle units, radiography equipments, reference weld samples etc. are not readily available in these welding hardware shops to enable the welders in the country to procure them. Again, the welding hardware shop owners claim that the welders have not been demanding the testing equipments; hence, they see no reason for stocking them for sale. That will lead to them incurring loss on those items. Moreover, observations show that, currently there is no manufacturing firm in the country that is into the manufacture and supply of any weld quality testing equipments which is rather the case in most developed as well as developing countries such as India and Malaysia [17].

Indeed, the situation whereby weld quality testing equipments and materials are virtually non available in the welding hardware shops in the country is undesirable. This is because a very large majority of the informal welders as well as a good number of the formal sector welders in the country have relegated weld quality inspection and testing practices in-house to the background due to their inability to obtain the needed weld quality testing and inspection logistics from the local welding hardware shops available in the country. To improve this situation, there should be effective interaction between the welders and the welding suppliers/dealers in the country. This will enable the latter to be aware of the weld quality equipments and materials needed by welders so they can import them into the country to be procured by the welders. Again, the government, the banks, as well as corporate organizations should help to establish industries solely to produce weld quality equipments and other similar equipments locally to make them available and accessible in the country.

\section{Conclusion}

In this paper, weld quality assurance practices in the metal welding industries in Ghana have been investigated. The study shows that weld quality assurance practices in the welding industries in the country are rather low and abysmal. This situation may well be attributed to the non-availability of welding standards, weld quality assurance personnel, weld quality assessment equipments and materials in the welding industries as well as low technical training levels of the welders in the country. Again, the welding equipments suppliers/dealers in the country are also not in a position to offer useful advice on weld quality assurance practices to the welders due to the suppliers' inability to train in relevant technical areas. Moreover, simple visual weld inspection and testing equipments such as Rulers, Magnifying Glass, Squares, Dye Penetrants, Pocket Telescopic Inspection Mirrors, Oval Inspection Mirrors, Welding Profile Gauges, Depth Gauges, reference weld samples, radiographic equipments, magnetic particle sets etc. are hard to come by in most of the welding hardware shops available in the country. For these reasons and many others, most of the welding industries in the country have relegated weld quality assurance practices to the background. To help reverse this trend and to infuse professionalism, efficiency and effectiveness in the welding sector in the country, it is absolutely imperative that the welders as well as the welding equipments suppliers/dealers take advantage of training programs offered by training institutions such as ITTU, GRATIS foundation, Danest West and so on to enable the welders and the suppliers to upgrade and update their technical competencies and technical training levels particularly in weld quality assurance practices. The welding industries in the country should do well to work according to acceptable welding standards. The welding hardware suppliers/dealers in the country must endeavor to import weld quality testing equipments into the country and make them available in their hardware shops to be procured by the welding industries in the country. Moreover, the government, the Banks as well as corporate organizations should help establish industries exclusively to produce more 
of the weld quality testing equipments and materials locally in order to make them available in the country. The curriculum and facilities on welding in the country's training institutions such as the universities and the polytechnics should be upgraded to enable them run higher diplomas and degree programs in welding technology. This will ensure that weld quality assurance specialists are trained locally to help instill professionalism in the welding industry in Ghana.

\section{References}

[1] S. E. Edusah, "The Informal Sector, Micro-Enterprises and Small-Scale Industries: The Conceptual Quan dary",2013.

[2] C. Hayes, 1998, “The ABC's of Nondestructive We Examination".

[3] Taylor and Francis, 2005, "Quality Assurance of Welded Construction", Elsevier Science Publishers Ltd, 2nd Edition, pp. 1-10.

[4] I.R. Levin, 1989, "Qualitative Approaches to Manage- ment". McGraw-Hill, Singapore.

[5] M.M.C Ondieki, E.T. Bisanda, and W.O. Ogola, "Impact of Education Level on Product Quality: Case Study of Arc Welding in Small Scale Metalworking Enterprises in Kenya",2013, pp. 001-008.

[6] American Welding Society, 2011, Vision for Welding Industry.

[7] Study.com, 2002-2015, Factsheet: Welding Education Requirements and Career [Online]. Available at http://study.com/welding_education.html [Accessed on 20th April, 2015]

[8] Wikipedia, the Free Encyclopedia, 2015, Factsheet: Welding [Online]. Available at http://en.wikipedia/wiki/welding. [Accessed on 25th April, 2015].

[9] A. S. Yasir, 2012, Factsheet: Study the Effect of Welding Joint Location on the Fatigue Strength and Fatigue Life for Steel Weldment [Online]. Available At http://www.asian-transactions.org/journals

/vol02issue04/ate/ate-80212044.pdf. [Accessed on 18th March, 2015].

[10] Springer Link, 1999, Factsheet: Fatigue Behavior of Welding Joints [Online]. Available at http://link.springer.com/chapter/10.1007\% 2F978-94-009-2277-8_24. [Accessed on 15th March, 2015]

[11] American Welding Society, 2015, Factsheet: Certified Welding
Sales Representative [Online]. Available at http://www.aws.org/certification/detail/ certified-welding-sales-representative. [Accessed on 5th April, 2015].

[12] Alcotech, 2015, Factsheet: Welder Qualifications [Online]. Available at http://www.alcotec.com/us/en/education /Training-and-Certification.cfm. [Accessed on 20th April, 2015].

[13] The Association of Welding Distribution, 2015, Factsheet: Careers in Welding [Online]. Available at http://www.awd.org.uk /careers.asp. [Accessed on 10th March, 2015].

[14] Wikipedia, 2015, Factsheet: Weld Quality Assurance [Online]. Available at http://www.awd.org.uk/careers.asp. [Accessed on 1st April, 2015].

[15] TWI, 2015, Factsheet: Welding Quality [On line]. Available at http://www.twi- global.com/capabilities/joining-technologies /welding-engineering/welding-quality/. [Accessed on 20th April, 2015].

[16] Inspecta, 2012, Factsheet: Welding Quality Assurance (ISO 3834) [Online]. Available at http://www.inspecta.com/en/Our-Services

/Certification/Management-Systems/ISO-3834-

Welding-Quality-Assurance/ [Accessed on 15th March, 2015]

[17] Caltech Engineering Services, 2015, Factsheet: Welding Inspection Instruments \& Accessories [Online]. Available at http://www.caltechindia.com/Welding-Testing-

Instruments-and-Accessories.htm [Accessed on 5th March, 2015].

[18] Alibaba.com, 2015, Factsheet: welding testing equip ment [Online]. Available http://www.alibaba.com/showroom/weldingtesting-equipment.html [Accessed on 5th April, 2015].

[19] Tony Anderson, 2007, Factsheet: The Fabricator.Com: Quality Inspections [Online]. Available at http://www.thefabricator.com/article/ testingmeasuring/quality-inspections. [Accessed on 1st May, 2015].

[20] Tony Anderson, 2002, Factsheet: Establishing Quality System for Welding [Online]. Available at http://www.thefabricator.com/article/ shopmanagement/establishing-quality- systems-for-welding. [Accessed on 14th March, 2015].

[21] Welding, 2012, Factsheet: The Importance of Visual Welding Inspection [Online]. Available at $\mathrm{http}: / /$ weldingdesign.com/safety-regulatory MalikVisualInspection. [Accessed on 5th March, 2015]. 